\title{
Barthes e Musil, como viver junto: as tabelas literárias de Gonçalo M. Tavares
}

\author{
Gisela Anauate Bergonzoni'
}

RESUMO: Esta comunicação apresenta uma análise de Roland Barthes e Robert Musil (2004), do escritor português Gonçalo M. Tavares. Trata-se de um texto literário peculiar, disposto em forma de planilhas, que o autor denomina "tabelas literárias". Busco mostrar como Tavares faz viver Roland Barthes para além das citações e referências ao autor francês. Para tanto, proponho uma leitura do texto à imagem invertida da "leitura drogada" de Sarrasine, de Balzac, que Barthes realizou num seminário entre 1967 e 1969 e que resultou no livro S/Z, de 1970. Busco também relacionar as "tabelas literárias" à ideia de "cálculo de prazer" contida no estudo de Barthes sobre a obra de Charles Fourier em Sade, Fourier, Loyola (1971). A proposta desta comunicação é aproximar as "tabelas literárias" de Tavares - um dispositivo de exatidão que emoldura um texto poético e fragmentário - ao movimento diacrônico que faz a própria obra de Barthes, partindo do entusiasmo com o formalismo nos anos 50 e 60 em direção ao prazer do Texto nos anos 70.

PALAVRAS-CHAVE: Roland Barthes; Robert Musil; Tabelas Literárias; Gonçalo M. Tavares; Prazer; Texto Fragmentário.

\section{Barthes and Musil, how to live together: Gonçalo M. Tavares' literary tables}

ABSTRACT: This paper presents an analysis of Roland Barthes e Robert Musil (2004), by the Portuguese writer Conçalo M. Tavares. It is a peculiar literary text, disposed in form of columns and rows, denominated "literary tables" by the author. I try to expose how Tavares makes Roland Barthes live in his text, beyond the quotations and references to the French author. Therefore, my reading of Tavares' text is based on an inverted image of the "drugged reading" made by Barthes of Balzac's short story Sarrasine in a seminar he held between 1967 and 1969, which resulted on the book S/Z (1970). I also seek to relate the "literary tables" to the idea of "calculation of pleasure" contained in Barthes' study of the oeuvre of Charles Fourier in Sade, Fourier, Loyola (1971). This paper proposes to liken Tavares' "literary tables" - a device of exactitude which moulds a poetic and fragmentary text - to the diachronic movement made by Barthes' oeuvre itself, from the enthusiasm with the formalism in the 50's and 60 's towards the pleasure of Text in the 70's.

KEYWORDS: Roland Barthes; Robert Musil; Literary Tables; Conçalo M. Tavares; Pleasure; Fragmentary Text.

0 objeto desta comunicação é um texto literário, mas que tem uma particularidade: Roland Barthes e Robert Musil (2004), do escritor português Gonçalo M. Tavares, é disposto em forma de planilhas - seu subtítulo, que aparece na folha de rosto do livro, é "tabelas literárias". Ele faz parte de um volume contendo também a novela $A$ perna esquerda de Paris. Apesar de esses dois textos terem uma relação, tratarei somente de Roland Barthes e Robert Musil, pois é o texto em que Gonçalo Tavares se filia mais intensamente e mais explicitamente à obra de Roland Barthes.

Gostaria primeiramente de apresentar o texto de Conçalo Tavares e de evidenciar meu método de leitura, que foi inspirado em Barthes, tomou um caminho inverso e logo voltou a andar lado a lado com Barthes. Em seguida, abordarei a forma escolhida das tabelas para dispor o texto. Minha ideia é aproximar Gonçalo Tavares de Barthes para além das citações e referências que estão presentes nesse texto. Parti, num primeiro momento, de uma vontade de entender como Barthes e Musil podiam viver juntos no texto de Tavares, mas o resultado é uma reflexão sobre como Tavares, de muitas maneiras, faz viver Barthes em suas "tabelas literárias".

\footnotetext{
${ }^{1}$ Doutoranda em Literatura Comparada na Universidade de Rennes II (França) e é bolsista da Capes. E-mail para contato: giselaab@gmail.com
} 
Nessa leitura, Musil será um pouco esquecido, mas, como escreve Barthes em $S / Z$, quando um crítico se esquece de apontar um dos sentidos de um texto, não se trata de uma falha, e sim da própria afirmação de que esse texto é plural. Para apresentar o texto de Tavares, descreverei o percurso que realizei quando tentei analisá-lo pela primeira vez. Um caminho de estranhamento, que consistiu na repetição, inúmeras vezes, de um mesmo movimento de leitura: primeiramente, procurar entender o significado de cada fragmento. Depois, tentar classificá-lo de alguma maneira quanto ao gênero. Em terceiro lugar, buscar encontrar a continuação de cada fragmento. E, em seguida, traçar a lógica de disposição desses fragmentos, visto que não havia propriamente uma continuação, mas uma relação entre eles.

0 texto de Tavares se inicia com uma primeira tabela, de cinco linhas por cinco colunas. Dentro de cada célula, há pequenos textos, alguns um pouco longos, ocupando várias linhas, outros tão curtos que não chegam a ser uma oração com sujeito e verbo. Muitas das células são espaços vazios. Essa primeira tabela se estende por duas páginas. Na terceira página do texto, inicia-se uma nova tabela - as tabelas não são numeradas, ao contrário dos capítulos -, que tem nove linhas por cinco colunas e que ocupa três páginas. No primeiro fragmento dessa tabela, lemos: "No subsolo encontraram vários cães enterrados" (TAVARES, 2004, p. 73). No subsolo de onde? Não se sabe, pois a tabela anterior não mencionava nenhum imóvel. Continuemos. Para onde? Meu impulso de leitora ocidental era sempre 0 de ler 0 fragmento posicionado imediatamente à direita do fragmento anterior: "Os canalhas avançam ao domingo para a missa e rezam com exatidão" (2004, p. 73). Seria um desses canalhas o assassino de cães do primeiro fragmento? Prossigamos. "Uma frase determinar o assunto da frase seguinte; tal nos parece um exagero, um excesso, a sensação de que algo nos quer obrigar a qualquer coisa" (2004, p. 73). Agora posso ter certeza de que não adianta procurar a continuação de cada fragmento, porque 0 escritor que estou lendo não está me contando uma história. Mas então do que tratam esses textos? ou, mais importante, o que são esses textos? É isso o que acabamos de ler uma ideia filosófica? Um aforismo? Uma asserção? Uma hipótese? Um começo, o meio ou o fim de um conto? Uma citação? Uma piada? Continuemos.

$\mathrm{Na}$ última linha da página, encontramos alguns fragmentos que continuam na página seguinte, tais como: "0 cão sem cabeça não rosnava" (TAVARES, 2004, p. 73-74) e "modificar a água. Trazer água à água. Modificá-la pelo aumento de sua quantidade" (2004, p. 73-74). Para seguir o fluxo da frase, é preciso praticamente memorizar seu início e sua posição (primeira, segunda, terceira, quarta ou quinta coluna). Por que essa dificuldade? os espaços em branco certamente ajudam a embaralhar os fragmentos, mas acredito que a escritura de Gonçalo Tavares, que joga com o inusitado das construções - um cão sem cabeça que não rosna, a possibilidade de modificar a água - intensifica a sensação de que não é possível prever a próxima linha, quanto mais o texto da próxima célula.

Por essa razão, tentei num primeiro momento imitar a "leitura drogada" de Barthes, que ele se propunha fazer no seminário sobre Sarrasine, de Balzac (ministrado na então denominada Ecole Pratique des Hautes Etudes en Sciences Sociales entre 1967 e 1969) e que mais tarde se transformaria no livro S/Z, publicado em 1970. Essa "leitura drogada" ("lecture droguée", BARTHES, 2011, p.79) se espelha no "Poema do haxixe", de Baudelaire, e consiste na repetição e no exame minucioso do que Barthes chama de "unidades" ("unités", 2011, p. 67): uma visão aumentada e completamente nova desses detalhes, que faz perder de vista o todo e que afasta, assim, a ideia de um significado único e total do texto. Porém, esse método visava analisar um texto "legível". Lembrando a definição de Barthes, o texto "legível" ("lisible") é o texto clássico, que almeja veicular um sentido e no qual o poder do leitor se limita muitas vezes a aprovaro texto que está lendo; já o texto "escritível" ("scriptible") é o texto moderno, plural, abrindo-se a múltiplas interpretações e à escritura do leitor (BARTHES, 1970). Não há dúvida de que o texto de Tavares é "escritível". Assim, se a leitura drogada não se aplica à perfeição, proponho 
aqui uma "leitura bêbada" das tabelas literárias de Gonçalo Tavares. Uma leitura que repete um movimento cambaleante diante de um texto difícil para então, possivelmente, cair de vez.

Desta maneira, mesmo com a pista de que nas tabelas de Tavares não vale a regra que costuma valer para o texto clássico, de que uma frase determina a frase que a segue, meu impulso foi o de procurar o fio que tece o texto - contrariamente ao propósito de Barthes no seminário sobre Sarrasine e em $S / Z$, que procurava as fendas do texto legível, os momentos que o tornavam plural. No primeiro momento da minha "leitura bêbada", procurei, numa massa de texto escritível, um fio de texto legível, aquele que conforta e aquece, aquele que diz que a vida segue. E de fato há algo que se repete nessa tabela de Tavares: a figura do cão, primeiramente morto no porão, depois sem cabeça, mais adiante, em outra célula da tabela, descrito como atento e estático e, finalmente, atropelado. Uma figura certamente nada reconfortante em si, mas que provoca um alento no leitor pelo fato de se repetir. Essa figura do cão aparece nos fragmentos da primeira coluna da tabela e também na tabela seguinte, o que sugere ao leitor que talvez exista um sistema que rege o texto. 0 cão se torna, desta maneira, um lampejo de história, um fio que tentamos seguir... mas que logo desaparece com o final do capítulo. Porque não há um fio: há uma trama de texto, um tecido que se tece e se expande na multiplicidade e que dá a ver a definição de Texto barthesiana. Antes de aceitar que não era possível encontrar um único fio para guiar minha interpretação do texto, continuei cambaleando ao procurar sistematizar a tabela como um todo. 0 que dizer das outras colunas? Se o cão é a figura dominante da primeira coluna, o que rege as outras colunas? Cheguei ao seguinte esquema, provisório, e que dizia respeito somente às primeiras tabelas do primeiro capítulo: a segunda coluna tentava traçar uma estranha biologia da sociedade e citava Walt Whitman; a terceira versava sobre o indivíduo em oposição à coletividade e identificava uma espécie de matemática da vida; a quarta evocava Robert Musil e indagava de onde vêm as ideias nos homens; a quinta exibia diversos nomes de poetas e citações.

A conclusão desta "leitura bêbada" das tabelas literárias é a de que não há lógica. Há poesia. E aqui cabe evocar outro texto de Gonçalo M. Tavares: 0 Senhor Henri e a enciclopédia (publicado em 2011 no Brasil e em 2005 em Portugal), um dos títulos da coleção "0 Bairro". Trata-se de uma série de livros, ainda em curso de produção e publicação, em que cada volume é dedicado a um habitante de um bairro imaginário. Esses personagens carregam nomes de escritores do cânone (senhor Calvino, senhor Brecht, senhor Walser, senhor Breton) que protagonizam pequenas histórias e que têm uma relação complexa com a obra dos seus epônimos. 0 senhor Henri é muito provavelmente Henri Michaux (e é o único em todos os livros do "Bairro" publicados até hoje a ser chamado pelo nome, e não pelo sobrenome). 0 senhor Henri, após tomar muitos copos de absinto, conta uma história curiosa: diz que nos tempos antigos havia duas matemáticas. Esta matemática que conhecemos hoje teria sido a que sobrou de um terrível embate:

... Quem nos diz, pois, que a matemática que temos não venceu pelo músculo e pela arma? ... a segunda matemática, a que se perdeu nos tempos, acredito que deu origem, por caminhos e subcaminhos, à poesia - disse o senhor Henri. ... mas isso não é uma certeza. ... é um cálculo poético. .... mais um copo de absinto, por favor. E rápido. (TAVARES, 2011, P.34)

Nessa reflexão do senhor Henri, além dadivertida ideia de que a poesia seria derivada de uma segunda matemática, chama atenção a expressão "cálculo poético", que pode ser lida quase como um resquício do "cálculo de prazer" que Barthes identifica na obra de Charles Fourier em Sade, Fourier, Loyola (2005). Gonçalo Tavares cita essa obra em suas tabelas literárias, sobretudo no que diz respeito aos ensaios sobre Sade, mas acredito que os ecos mais 
importantes no trabalho de Tavares se encontram no que Barthes escreve sobre Charles Fourier ${ }^{2}$ : na leitura barthesiana, Fourier opera uma série de cálculos para transformar o trabalho em prazer na sociedade harmônica que ele teoriza. Barthes escreve sobre os números delirantes de Fourier, que taxinomiza e contabiliza em seus textos todos os elementos da sociedade: 0 marido é infeliz no casamento por oito razões; nos tempos de Varrão em Roma havia 278 opiniões contraditórias a respeito da verdadeira felicidade e assim por diante. Barthes também se deixa levar pelo deleite contábil em seu seminário sobre Sarrasine, em que identifica 700 unidades de

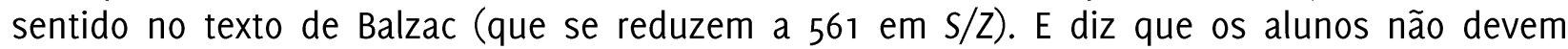
ironizar esse número; que é preciso fazer como Fourier, "que degustou largamente o prestígio dos números, e de uma maneira infinitamente mais poética do que todos os nossos humanistas". Ainda segundo o que Barthes escreve em suas notas do seminário, "é preciso lembrar que o direito ao número é o direito absoluto à Utopia!". Ora, esse "direito ao número" é precisamente o que se concede Tavares em suas tabelas, que emolduram o texto em um dispositivo de exatidão. Tavares escreve em uma tabela do segundo capítulo: "Por que razão a coluna de uma tabela não será o lugar mais apropriado para o desenvolvimento de uma frase?" (2004, p. 95). Esse fragmento é repetido algumas células adiante, até que a voz narrativa se pergunta: "E onde colocar os números?", propondo-se uma experiência (2004, p. 95). Tentei encontrar a lógica desses números, combinados com nomes de autores e citações de Joyce, mas falhei mais uma vez. Tenho a impressão de que esse desejo de descobrir o sistema por trás do texto de Tavares tem menos a ver com uma vontade de encontrar o conforto de um sentido, do que há de legível em um texto ilegível (ou escritível) do que com o reflexo de racionalidade que desperta a forma das tabelas. Tavares não o faz para instaurar o pânico entre os críticos literários que não sabem usar as planilhas de Excel (e eu me incluo entre eles), mas para "degustar o prestígio dos números" de maneira poética. Na segunda tabela do quarto capítulo, Tavares cita Barthes:

Roland Barthes fala dos 'lugares especiais' da linguagem em oposição aos 'lugares comuns'. Escrevo: nenhum ser humano está num lugar insólito se leva consigo frases miseráveis. Pois é a linguagem que localiza o Homem. São as frases raras que viajam e conhecem. (2004, p. 106)

Mesmo se a referência aos lugares comuns contra os lugares especiais pode vir do estudo de Barthes sobre a Antiga retórica (1970) considero pertinente aproximar esse desdobramento que faz Tavares, sobre as frases raras, ao prefácio de Sade, Fourier, Loyola, em que Barthes afirma que esses três autores são "logotetas", fundadores de uma língua própria, que não é a língua da comunicação. Barthes escreve: "A língua nova deve surgir de um vazio material; um espaço anterior deve separá-la das outras línguas comuns, ociosas, ultrapassadas..." (2005, p. X). A meu ver, Gonçalo Tavares tem a pretensão de ser também um fundador de linguagem, de fazer suas frases raras - que provocam tanto estranhamento a ponto de nos confundirmos na continuação de um fragmento quando há quebra de página - viajar para bem longe dos lugares comuns. E esse espaço que separa a língua que viaja da língua comum se exprime também pelos espaços vazios que compõem as tabelas literárias, que abordarei novamente adiante.

Talvez seja na figura de Fourier que esteja a articulação entre Roland Barthes e Robert Musil do texto de Tavares, porque também em Musil pode-se dizer que existe um "cálculo de prazer". A matemática tem um papel fundamental na obra do autor austríaco: 0 homem sem

\footnotetext{
${ }^{2}$ Ver os fragmentos "0 cálculo de prazer" e "Números" (BARTHES, 2005).

${ }^{3}$ Minha tradução. Na versão original, lê-se: "Mais il faut faire comme Fourier, qui a goûté largement le prestige des nombres, et d'une manière infiniment plus poétique que tous nos humanistes (...)". (BARTHES, 2011, p. 73)

4"Et puis se rappeler que le droit au nombre est le droit absolu à l'Utopie!" (BARTHES, 2011, p. 73)
} 
qualidades (1930) relata a busca de uma pureza, de uma essência, de um despojamento de todos os atributos, uma abolição da realidade para que se encontre o ser. A matemática é um meio para Ulrich, o personagem central, tentar se tornar esse homem totalmente novo e livre, pois ela é a linguagem da abstração. No romance 0 jovem Törless (1906), o protagonista, estudante de internato, tem uma epifania quando começa a refletir acerca dos números imaginários após uma aula de Matemática.

Qual o resultado do nosso "cálculo poético" das tabelas literárias? 0 que resta desse texto retalhado em linhas e colunas? A resposta possível é: o fragmento. Porque além de configurarem o que chamei acima de "dispositivos de exatidão", as tabelas evidenciam os cortes e a ausência de continuidade entre os trechos. Gonçalo Tavares realiza seu elogio ao fragmento não apenas na forma. Como lemos na primeira tabela do oitavo capítulo: "É necessário muito tempo para construir um fragmento. Pensa nas ruínas" (2004, p. 133). Essa exaltação ao fragmento vai ao encontro das reflexões de Barthes em A preparação do romance, desde 0 estudo do haicai até a distinção entre o Álbum e o Livro, onde o autor faz uma poética da notação como aquela que diria melhor a modernidade do que a forma romanesca. Ora, a imagem da ruína é precisamente a que utiliza Barthes na segunda parte de $A$ preparação do romance para descrever o Álbum: "A ruína, com efeito, não está do lado da morte: ela é viva como Ruína, consumida como tal, esteticamente constituída, germinativa"n. A ruína vive na literatura e, o mais importante, ela é germinativa. 0 que nos leva a outro trecho das tabelas literárias de Conçalo Tavares: no nono capítulo, que tem como subtítulo "Ensaio sobre Roland Barthes e Robert Musil (a literatura)", lemos: "Porque é indispensável não terminar. Deixar a quem lê a hipótese de fazer uso de uma ferramenta que ainda modifique algo" (TAVARES, 2004, p. 153). 0 fragmento, a ruína, além de vivo, faz viver, dá origem a outra vida. Ele é germinativo, diz Barthes, e aqui ele está certamente pensando na escritura do leitor - como Tavares, que mostra que é indispensável que o autor não termine o que escreve.

É importante lembrarmos que quando Barthes fala sobre o Álbum em oposição ao Livro, ele está retomando a distinção de Mallarmé em seu famoso projeto do Livro, que trataria da totalidade das coisas que existem. Ora, as folhas deixadas por Mallarmé são cobertas de números - cálculos sobre a viabilidade financeira dessa obra infinita, custos de cada performance de leitura do Livro... Mallarmé fez também seu "cálculo poético", seu "cálculo de prazer", no qual números e literatura (em sua forma mais utópica, como no falanstério de Fourier) convivem. Mas o que Barthes retém do Livro de Mallarmé em A preparação do romance é a ruína desse projeto: é o Álbum o futuro do Livro (que nunca se fez), é o que permanece vivo. Nas tabelas de Conçalo Tavares, além da disposição em fragmentos e dos números que habitam as tabelas junto com o texto literário, há muito de Mallarmé nessas casas em branco, nesse respiro emoldurado que deixa o leitor livre para, mais do que interpretar, escrever ele mesmo. A angústia diante da página branca de Mallarmé se repete nas tabelas de Tavares, ela é uma angústia de dar forma à literatura, como se Tavares sonhasse ele também com uma literatura pura, livre de qualquer imperativo. Em uma das células da primeira tabela, lê-se: "Mesmo a página em branco é exterior à literatura, uma imposição do exterior, do que não é literatura." (TAVARES, 2004, p. 71)

Nesse sentido, o texto de Tavares é um exercício de libertação, onde se faz uma reflexão ampla, sobre todas as amarras da literatura - desde o gênero literário até a página, a ordem de leitura, o espaço do texto. Ele questiona inclusive as determinações que dizem respeito à própria matéria de que a literatura é feita: a língua. Gonçalo Tavares escreve em um trecho da primeira tabela do quinto capítulo: "Repara que nenhuma frase é privada. Ao existirem as frases

\footnotetext{
${ }^{5}$ Minha tradução. No texto original, lê-se: "La ruine, en effet, n'est pas du côté de la mort: elle est vivante comme Ruine, consommée comme telle, esthétiquement constituée, germinative." (BARTHES, 2003, p. 257)
} 
tornam-se públicas, colectivas, mesmo quando ditas em voz baixa por alguém que se encontra sozinho, um segundo antes de se matar" (2004, p.114-115). A conclusão de Tavares nessa tabela é que "só o silêncio é individual" (p. 115). 0 autor está preocupado, como Barthes em Aula (conferência no Collège de France datada de 1977), com o condicionamento que se sofre ao se dobrar a um sistema. Ora, a língua é um sistema, não há como escapar - só pelo silêncio, pelo impossível. Cito Barthes:

Na língua, (...) servidão e poder se confundem inelutavelmente. Se chamamos de liberdade não só a potência de subtrair-se ao poder, mas também e sobretudo de não se submeter a ninguém, não pode então haver liberdade senão fora da linguagem. Infelizmente, a linguagem humana é sem exterior: é um lugar fechado. Só se pode sair dela pelo preço do impossível (...). Só nos resta (...) trapacear com a língua, trapacear a língua. Essa trapaça salutar, essa esquiva, esse logro magnífico que permite ouvir a língua fora do poder, no esplendor de uma revolução permanente da linguagem, eu a chamo, quanto a mim: literatura. (1989, p. 15-16)

Quando Gonçalo Tavares sistematiza um texto poético como o seu em tabelas, ele evidencia uma estrutura imaginária que é minada pelo próprio texto. É como se esse trabalho de Tavares ilustrasse o movimento que faz a obra de Roland Barthes, partindo do entusiasmo com a estrutura em direção ao prazer do Texto: a semiologia, a catalogação e a classificação de objetos e de signos às quais Barthes se dedicou caminha para sua própria explosão no gozo do leitor e no prazer do Texto nos anos 70. Não é por acaso que escolhi o método usado por Barthes em S/Z para inspirar minha "leitura bêbada": é nesse momento da obra barthesiana que se pode ver com certa nitidez a transição da semiologia, da análise estrutural das obras, para 0 que Barthes chamará em seguida de "teoria do Texto". Nas notas do seminário sobre Sarrasine, Barthes escreve que seu objetivo não é "esgotar" a obra de Balzac ou procurar o seu sentido secreto. Trata-se, escreve Barthes, não de "descobrir a obra, mas de cobri-la de uma

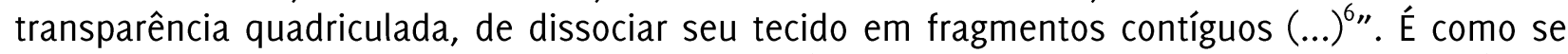
Gonçalo Tavares adiantasse esse trabalho do crítico em seu texto e adicionasse, ele próprio, essa transparência quadriculada que o corta em fragmentos.

É interessante como essa transição da obra barthesiana se opera por meio da própria semiologia, como diz Barthes. Afinal, ele cita Saussure, o grande inspirador do estruturalismo, como um dos autores que o fizeram desviar da semiologia para encontrar o Texto. Em "Saussure, o signo, a democracia", de 1973, Barthes afirma que a arbitrariedade do signo instaura uma grande instabilidade na língua, que permite entrever a ausência de lastro dos significantes. A própria sistematização da língua permite notarmos que ela não passa de uma convenção - e, aqui entra minha interpretação, essa fenda aberta no sistema pelo próprio sistema exibe que por trás da estrutura há vertigem. E é justamente na fenda que o prazer se instala, como escreverá mais tarde Barthes em 0 prazer do texto (1975). É o que eu vejo nas tabelas literárias de Tavares: no momento em que linhas e colunas são traçados, cria-se um sistema, um jogo. Ainda na análise que Barthes faz da escrita de Charles Fourier, lemos:

(...) Fourier ataca o 'sistema' civilizado [repressivo], demanda uma liberdade integral [dos gostos, paixões, manias, caprichos]; seria, portanto, de esperar uma filosofia espontaneísta, mas é exatamente o contrário que se tem: um sistema desvairado, cujo excesso mesmo, cuja tensão fantástica ultrapassa o sistema e realiza o sistemático, isto é, a escritura: a liberdade nunca é o contrário da ordem, é a ordem paragramatizada: a escritura deve mobilizar ao mesmo tempo a imagem e seu contrário. (BARTHES, 2005, p.128).

\footnotetext{
6 "Il ne s'agit pas de découvrir l'œuvre, mais de la couvrir d'un transparent quadrillé, de dissocier son tissu en fragments contigus (...)". (BARTHES, 2011, p. 65)
} 
As "tabelas literárias" de Tavares podem ser definidas também como um "sistema desvairado". Podemos até imaginar o autor se propondo um desafio à la Oulipo (Ouvroir de littérature potentielle), um rito ou uma fórmula matemática que guiasse a produção do seu texto, para, em seguida abandoná-lo. Porém, essa imagem não ilumina minha leitura de Roland Barthes e Robert Musil. Meu objetivo nesta comunicação foi entender como o escritor liberta 0 Texto por meio de uma aparência de ordenação, de que maneira ele realiza a escritura através do sistemático. Como se o traçado das tabelas permanecesse, mas as regras jamais realmente impostas explodissem, ou se dissolvessem, e as frases escorregassem entre as colunas, por entre essas fendas invisíveis, exibindo a vertigem da língua - e todo o seu prazer.

\section{REFERÊNCIAS}

BARTHES, R. S/Z. Paris: Seuil, 1970. "Ancienne rhétorique: aide-mémoire". Communications, Paris, v.16, n.16, p. 172-223, 1970. - Aula. Tradução de Leyla Perrone-Moisés. São Paulo: Cultrix, 1989.

- "Saussure, o signo, a democracia". In: A aventura semiológica. São Paulo: Martins

Fontes, 2002. . La préparation du roman I et II: Cours et séminaires au collège de France (1978-1979 et 1979-1980). Paris: Seuil, 2003. - Sade, Fourier, Loyola. Tradução de Mário Laranjeira. São Paulo: WMF Martins Fontes, 2005. - Sarrasine de Balzac: Séminaires à l'Ecole pratique des hautes études 1967-1968, 19681969. Paris: Seuil, 2011.

TAVARES, G. M. A perna esquerda de Paris, seguido de Roland Barthes e Robert Musil. Lisboa: Relógio d'Água, 2004. . O senhor Henri e a enciclopédia. Rio de Janeiro: Casa da Palavra, 2011. 